\title{
Agile management in the context of Russian industrial sector
}

\author{
Elizaveta A. Gromova* \\ Peter the Great St. Petersburg Polytechnic University, Saint-Petersburg, Russia
}

\begin{abstract}
The Fourth Industrial Revolution is a new era in the development of mankind, which makes changes in the economic sphere. Agile approach is a suitable management model that can counteract to such issues as uncertainty and rapid changes in business environment. The goal of the study is to analyze this model and to relate it to the Russian industrial sector. Theoretical and practical aspects of the agile concept are presented. The conclusion about the effectiveness of the agile management that meets the necessary modern requirements, for the Russian industry development is drawn.
\end{abstract}

\section{Introduction}

The Fourth Industrial Revolution is a relatively new phenomenon in the world but has managed to penetrate into the minds of many people. The dynamics of shifts in production paradigms is logical. So, in the 1760s, the First Industrial Revolution took place. From this moment, with the beginning of industrial application of the steam engine and active construction of the railroads, the era of ineffective manual work ended and prompt development of machine production began. The end of the XIX century was marked by large-scale electrification and the widespread introduction of the manufacture of conveyors, marked the beginning of mass production. This period was called the Second Industrial Revolution. In the 1960s, the Third Industrial Revolution, which was called computer or digital revolution, began. The invention and widespread use of semiconductors, computers, and later - personal computers and the Internet have become its starting mechanism. The turn of the millennia was the beginning of the Fourth Industrial Revolution. It has brought massive use of the Internet, the development of miniature production devices, learning machines and artificial intelligence. Digital technologies based on hardware and software are not an innovation in themselves, but by uniting into global networks, constantly improving, integrating everything into new spheres of human life, they steadily transform the global economy, moving further away from the level of the third industrial revolution. The fundamental nature of the current changes, which makes it possible to talk about their uniqueness, lies in [1]:

1. The pace of development. While the transition from steam engines to electricity took a century and a half, digital technologies are developing at an enormous pace; it is an exponential rate of development.

\footnotetext{
${ }^{*}$ Corresponding author: lizaveta-90@yandex.ru
} 
2. The breadth and depth of distribution. The diversity and level of technological development bring about unprecedented changes in all areas of human life.

3. Systemic changes. This is not about the local application of different technologies, but about their merging, integrating into the system, which entails profound structural changes that occur at the global level in almost all countries, companies, industries and society as a whole.

Therefore, in the context of the industrial sector of the economy development, companies need new management concepts that are effective in modern conditions.

The methodology of agile management acquires particular relevance in the context of the Fourth Industrial Revolution formation. It is a strategy whose aim is to achieve a sustainable development by the company by adapting to all kinds of unpredictable changes. The theoretical and practical issues of agile approach are explored by many scientists. It is significantly that this methodology has received wide recognition abroad. In contrast to the developed countries agile management has not yet received sufficient development in Russia. Thus, the goal of the study is to analyze this model and to relate it to the Russian industrial sector.

\section{Methods}

The agile management $[3,4,6,7,8,9,13,15,17,18]$ becomes particularly relevant in the context of the Fourth Industrial Revolution formation. This model is able to solve the most urgent problems for today, which consist of uncertainty and rapid changes in business environment. Initially, the agile methodology has successfully proved itself in the field of information technologies. The aforementioned software development methodology succeeded in squeezing the traditional for this industry - the waterfall model. The essence of the agile system is based on the following fundamental principles:

- technical units in cooperation with the business department are located in an open area;

- test scripts are developed before programming stage;

- daily morning meetings with a brief discussion of the problems encountered;

- the development process consists of "sprints" (work cycles lasting from one to four weeks). The output of each cycle is the working code.

So, agile management can be defined as short cycles of product development that deliver product incremental updates rapidly based on the changing needs of the customer. This methodology is opposite to the well-known waterfall project management, which values extensive planning and preproduction.

According to a study conducted by Bain \& Company, more than $90 \%$ of IT organizations report the use of agile methodology, at least in terms of software development, and $45 \%$ of individual respondents work in organizations that use agile management methods for most of their development teams. As the main result, the vast majority (about 95\%) of companies plan to continue to adhere to the principles of this methodology. Quantitative indicators of success declared by the companies confirm the achieved result [19]:

- $76 \%$ reduced risk of projects;

- $77 \%$ were able to speed the product's time to market;

- $79 \%$ increased morale and motivation of employees;

- $84 \%$ increased performance teams;

- $87 \%$ gained the ability to manage changing priorities.

The principle of functioning of agile methodology in information technologies sphere is transformed into its application in the most effective management strategy within the framework of the Fourth Industrial Revolution. The main regularities of the mechanism for 
introducing and using the model under consideration, with an emphasis on the scale of activities and taking into account modern means of developing communications are preserved. Next, it is necessary to highlight a number of characteristic features of the agile management:

- an extensive partner network of companies;

- dual operating system, consisting of the synthesis of a classical hierarchical organizational structure and a dynamic network structure, designated by Kotter [11], as necessary to match modern organizations with the requirements of a rapidly changing business environment;

— wide application of cloud technologies for integration of interacting companies among themselves and with the external environment;

- multidisciplinary team of the main company;

— avoiding multitasking;

- rapid reconfiguration of labor and material resources;

- high level of customization;

- minimization of losses from possible, unexpected negative changes.

According to the study of the international consulting company McKinsey in 2017, the main potential benefits of agile management in industrial sector are presented in Figure 1 $[20]$.

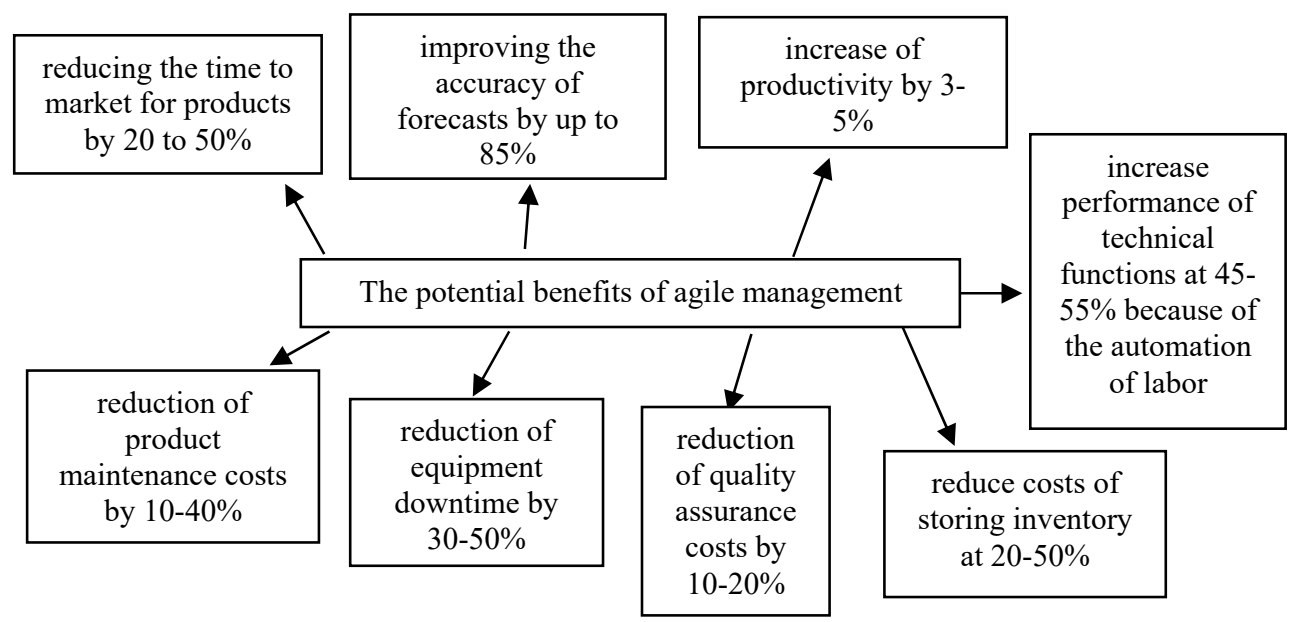

Fig. 1. The main potential benefits of agile management in industry (developed by the authors on the basis of the research of the consulting company McKinsey in 2017).

\section{Results and discussions}

Now there are no effective management models in the Russian industrial sector. Industrial sector includes all branches of production. First of all, there are processing industry, extraction of minerals, production and distribution of electricity, gas, water. Thus, industrial sector refers to not only IT-oriented branches. But in the context of new industrial revolution IT-oriented branches are most susceptible to current changes. Russia is at the start of agile transformation. Normative legal documents are just beginning to be adopted with the aim of building a new economic paradigm under the conditions of the Fourth Industrial Revolution.

The digital economy is the fundamental basis of the Fourth Industrial Revolution. As a result, the introduction of modern digital technologies in various fields of activity, primarily 
in industry, is a priority for the development of the national economy. Many efforts and actions need to be applied to the development of the digital economy in Russia $[2,5,10,12$, $14,16]$. For the first time the task of forming a digital economy was identified by the President of the Russian Federation V.V. Putin in his annual address to the Federal Assembly in 2016: "... launch a large-scale system program for the development of the economy of a new technological generation, the so-called digital economy". Approved by the decree of the Government of the Russian Federation of July 28, 2017, No. 1632-r, the Digital Economy of the Russian Federation program, guided by the "Strategy for the Development of the Information Society in the Russian Federation for 2017-2030", defines the digital economy as an economic activity, a key factor in production which is data in digital form, and contributes to the formation of an information space, taking into account the needs of citizens and society in obtaining qualitative and reliable information, development and the information infrastructure of the Russian Federation, the creation and application of Russian information and telecommunication technologies, as well as the formation of a new technological basis for the social and economic sphere.

At the moment, the first measures to adapt to the digital revolution are recorded in the Russian services sector. First of all, the banking sector and the telecommunications industry are attempting to implement the agile approach. In Sberbank since 2016 the agile transformation is being counted, the main purpose of which is to speed up the withdrawal of new products to the market. So, when working on the old model from the appearance of the idea to the release of the product on the market could take up to 2 years, according to the agile model, Sberbank plans to fit into several months. Also, management decisions should be developed and adopted at a high rate, the bank management system should become cheaper, and innovation activity - more intensive. The first step was the selection of a consulting company to prepare a detailed program for the transformation of the structure and management model based on the target model of the agile organization.

The telecommunications services sector development is crucially necessary for the strategic development of all sectors of Russian economy. Also, it is distinguished by its attempts to switch to agile. And foreign experts predict a major breakthrough in this sector in the next 5 years. However, now the development of the telecommunications market is at the beginning. The sluggish revenue dynamics pushed the operators either to enter into partnerships with digital companies or to transform into them. So, the owner of the company «VimpelCom» M. Fridman formulated the task as: "to move away from its roots in the communications industry to much more modern - IT and hi-tech". In turn, «MegaFon» has more specific plans to conquer the digital segment. The company intends to buy a controlling stake in the Internet holding Mail.ru Group for 740 million dollars. The deal should return MegaFon's performance to sustainable growth and is part of the company's new strategy.

In the context of the telecommunications services sector case study of the Vodafone Turkey, which embarked on the path of agile transformation in 2014 acquires special value. Agile transformation has been set as 3 steps. In the first step, a pilot team was established and for several sprints its progress had been tracked. Due to the observed improvements of the pilot team especially in productivity, the pilot team had tripled its throughput rate at the end of its first three months, then, it had been decided to move forward with the second step, scaling step, via establishing new scrum teams. Around 5 months after moving forward with the scaling step, scrum teams' throughput was observed to be two times more than before. In addition to that, significant reductions were recorded in defect rate and customer complaints inside these scrum teams. The third step was enterprise adopting with the aim to grow agile culture. Telecommunications industry in Turkey is highly competitive and agile transformation has started to shorten time to market and improve quality in order 
to be able to provide competitive advantage to the business. And these goals have been achieved.

In general, the pace of progress in implementing the agile management in the telecommunications sector and in the banking sector in Russia is roughly comparable.

While Russian industrial sector is looking for ways to adapt to the new realities of the digital revolution, PricewaterhouseCoopers has carried out a review of the implementation of the Fourth Industrial Revolution in industrial companies in 2016. More than two thousand respondents out of nine major industry sectors and 26 countries took part in the study. The main results are [21]:

— annual revenue from digital solutions amounted to 493 billion dollars USA;

— the annual benefit from cost optimization and efficiency gains amounted to 421 billion dollars USA;

— the annual investment in digital technology amounted to 907 billion dollars USA.

Timely implementation of digital transformation in the industry is a strategic imperative for Russia, whose economy is closely connected with such industries as mining and processing of natural resources and engineering, and where there has not yet been much success in the implementation of agile management. Thus, the density of robotization of production at Russian enterprises is more than 20 times lower than the world average. Now Russian enterprises, representing various industries are given a special chance to reduce the backlog of world leaders. At the moment there are no unambiguous countries - leaders of the Fourth Industrial Revolution.

\section{Conclusions}

Following the results of the study, it is necessary to draw the following conclusions:

1. the Forth Industrial Revolution possesses a tremendous potential for transforming the Russian industry, which was traditionally considered quite conservative in the use of digital technologies;

2. the rapid growth in the pace of technology development, the depth and scale of their application in the Digital Revolution provokes the introduction of modern management models in industry, which take into account the requirements of the new industrial paradigm;

3. methodology of agile management meets the contemporary requirements of the new era of the world industrial development;

4. Russian industry is at the start of agile transformation. Russian telecommunications sector and banking sector have the greatest success, having managed to embark on the path of agile management implementation;

5. the agile approach is a promising model for Russian industrial sector in the context of modern trends of the world industrial development.

\section{References}

1. K. Schwab, The fourth industrial revolution (Crown Publishing Group, 2016)

2. A. Bril, O. Kalinina, I. Ilin, MATEC Web of Conferences 106, 08010 (2017)

3. M. Cohn, K. Schwaber, Agile Times, 1 (1), 10-12 (2003)

4. R. Dubey, A. Gunasekaran, The International Journal of Advanced Manufacturing Technology, 76, (9-12), 2147 (2014)

5. V.V. Glukhov, I.V. Ilin, A.B. Anisiforov, ACM International Conference Proceeding Series (2015) 
6. J. Goodpasture, Project management the agile way: Making it work in the enterprise (J. Ross Publishing Inc., 2010)

7. A. Gunasekaran, International Journal of Production Research, 1-13 (2017)

8. V. Hallgren, J. Olhager, International Journal of Operations \& Production Management, 29, 976 (2009)

9. J. Highsmith, Adaptive software development: a collaborative approach to managing complex systems (Dorset House Publishing, 2000)

10. I. Ilin, A. Levina, A. Abran, O. Iliashenko, ACM International Conference Proceeding Series, 232 (2017)

11. J. Kotter, Accelerate. Building strategic agility for a faster-moving world (Harvard Business Review Press, Boston, 2014)

12. T. Kuladzhi, A. Babkin, S.A. Murtazaev, Advances in Intelligent Systems and Computing, 692 (2018)

13. C. Larman, Agile and iterative development: A manager's guide (Addison-Wesley Professional, 2004)

14. I. Rudskaya, D. Rodionov, Academy of Strategic Management Journal, 16 (2) (2017)

15. L. M. Sanchez, R. Nagi, International Journal of Production Research, 39 (16), 3561 (2001)

16. E.S. Balashova, E.A. Gromova, Espacios, 38 (41), 30 (2017)

17. K. Schwaber, The enterprise and Scrum (Microsoft Press, 2007)

18. J. Sutherland, J. J. Sutherland, SCRUM. The art of doing twice the work in half the time (Crown Publishing Group, 2014)

19. URL: http://www.bain.com/publications/articles/agile-innovation.aspx (accessed 17.12.2017)

20. URL:https://www.mckinsey.com/ /media/McKinsey/Locations/Europe\%20and\%20Mi ddle\%20East/Russia/Our\%20Insights/Digital\%20Russia/Digital-Russia-report.ashx (accessed 05.09.2017)

21. URL:https://www.pwc.ru/ru/technology/assets/global_industry-2016_rus.pdf (accessed 16.01.2018) 